\title{
Eradication of Staphylococcus aureus and MRSA in the Nares: A Historical Perspective of the Ecological Niche, with Suggestions for Future Therapy Considerations
}

\author{
Eric Bornstein \\ Nomir Medical Technologies, Woodmere, NY, USA \\ Email: ebornstein@nomirmedical.com
}

How to cite this paper: Bornstein, E. (2017) Eradication of Staphylococcus aureus and MRSA in the Nares: A Historical Perspective of the Ecological Niche, with Suggestions for Future Therapy Considerations. Advances in Microbiology, 7, 420-449.

https://doi.org/10.4236/aim.2017.76034

Received: April 28, 2017

Accepted: June 12, 2017

Published: June 15, 2017

Copyright $\odot 2017$ by author and Scientific Research Publishing Inc. This work is licensed under the Creative Commons Attribution International License (CC BY 4.0)

http://creativecommons.org/licenses/by/4.0/

(c) (i) Open Access

\begin{abstract}
Nasal colonization with pathogenic bacteria continues to present challenges for patients undergoing surgical procedures, and for the physicians that treat them. Even as molecular medicine produces ever faster and improved data sets for clinicians, it would benefit all medical personnel attempting to decolonize the nose to better understand the historical nasal decolonization data with specific reference to the ecological niche for these bacteria, as it has been recorded for more than a century. Much of the historical data points to the largest ecological niche for nasal Staphylococcus aureus as the vibrissae of the vestibulum nasi. A careful study shows that any topical antimicrobial preparation needs to successfully penetrate the deepest recesses of these specialized nasal hair follicles, if decolonization is to be adequately accomplished. This review highlights the most relevant data of the last 140 years concerning the staphylococcal ecological niche of the vibrissae. Also to be discussed will be a historical review of topical Mupirocin. Almost thirty years after its FDA approval, Mupirocin is still the most widely used topical antibiotic for decolonization therapy around the word. Correspondingly, new experimental in vitro data will be presented showing the differing efficacy of Mupirocin against multiple strains of HA-MRSA and CAMRSA, based solely on the commercial topical formulation (non Mupirocin ingredients) that acts synergistically with the Mupirocin. Finally, the review will discuss why an understanding of these historical data is a vital component to integrate into any new or augmented nasal decolonization therapy.
\end{abstract}

\section{Keywords}

MRSA, Mupirocin, Topical, Nasal Decolonization 


\section{Introduction}

Staphylococcus aureus ( $S$. aureus) is a gram-positive cocci that is in the human commensal microbiome. As a potential pathogen, $S$. aureus colonizes both the skin and various mucosal surfaces in several parts of the body, including the nasal cavity (nares) of roughly $30 \%$ of the human population [1]. In the last twenty-five years, different groups have studied many of the different elements thought responsible for long-term staphylococcal nasal carriage. Many of these studies have placed an emphasis and focus on bacterial binding to mucosal cells and secreted mucin [2] [3] [4] [5]. There is no doubt that $S$. aureus exists in secreted mucin and on mucosal cells in the nares, but the larger historical record disagrees with the assertion that the mucosal area, posterior to the vestibulum nasi, is the primary ecological niche for this important commensal bacteria.

If the goal for infection prevention is to achieve the highest possible efficacy in any nasal decolonization therapy, the correct etiologic factors first need to be identified in the accurate ecological niche [6]. This requires a thorough understanding of historical data describing $S$. aureus colonization in the nose. With the primary instrument of nasal decolonization therapy today being the topical application of Mupirocin nasal (in a paraffin base), a reexamination of the successes and failures of this therapy from a historical perspective is essential. To reinforce this historical chronology, new experimental data will be presented showing the differing efficacy of Mupirocin against multiple strains of HAMRSA and CA-MRSA based solely on the commercial formulation itself (non Mupirocin ingredients) that acts synergistically with the Mupirocin.

The following is a chronological and retrospective examination of bacterial colonization of the nares. This analysis has documented the primary ecological niche inside the nares for $S$. aureus colonization as the vibrissae (specialized hair follicles) of the vestibulum nasi. It is the premise of this review, after examination of 140 years of reports and scientific evidence, that failure of nasal decolonization therapy occurs not only as a result of bacterial resistance to topical antimicrobials and bacterial biofilm formation, but also in large measure from a failure of the topical antimicrobial to fully penetrate the deep recesses of the nasal vibrissae.

Careful study of these largely overlooked segments of noteworthy historical data produced by physicians and researchers in the last 140 years illuminates past errors in nasal decolonization efforts and leads to insights for future therapy. In analyzing these reports, there are a series of accumulated facts and data that a priori point conclusively to vestibulum nasi and the vibrissae as the area of greatest nasal staphylococcal colonization. Specifically, the vestibulum nasi is the distinctive band of skin, containing the vibrissae and sebaceous glands. This band of skin is the ecological niche for Staphylococcal colonization, to a far greater extent than the deeper mucosal tissue posterior to the vestibulum nasi. This report will examine the historical literature regarding Staphylococcal carriage in the human nares, culminating with the most recent modern reports, up to the present day. Emphasis will be placed on the vestibulum nasi and the vi- 
brissae as the center of Staphylococcal colonization in the nares. At the end of this review, discussions will focus on future considerations for improved decolonization therapy in this important area.

\section{The Vibrissae}

$A b$ initio the data concerning infections in the nose began to accumulate in 1875, when William Spence Watson, a surgeon in London warned other physicians to be aware of sycosis (inflammation of the hair follicles caused by bacteria) that "sometimes attacks the roots of the hair (vibrissae) within the entrance to the nostril" [7]. Seven years later, Ogston isolated $S$. aureus from purulence in a human abscess, and observed "grape-like" clusters, which he termed "Staphylococci," from the Greek staphylé ("bunch of grapes") [8]. In 1884, the German physician and microbiologist Rosenbach further classified the Staphylococci as "aureus" when he observed the bacterial colony's characteristic yellow or gold pigmentation [9].

In 1886, Baber first described the nares as being "lined with skin, which is plentifully supplied with short stout hairs, vibrissae" [10]. This was followed in 1902 by one of the first accurate descriptions of the human nares in a medical text from Cunningham, the Scottish physician and anatomist. Cunningham's anatomy text defined the vibrissae, and depicted these hairs in an accurate anatomical figure of the nostril. Cunningham explained, "The vestibule is lined by skin and contains hairs and sebaceous glands. The hairs or vibrissae, springing from its lower half, are stout and curved downwards to guard the entrance to the nostril." [11]. Then in 1906, in his text The diseases of the nose and its accessory sinuses, Lack described the anterior part of the nasal vestibule as "studded with short stout hairs, or vibrissae, and contains large sebaceous and sweat glands." [12].

It is these vibrissae and sebaceous glands, first described from 1886-1906 as the skin that makes up the most anterior section of the nares, that are in most cases overlooked by the modern medical community in staphylococcal decolonization studies. However, as will be shown below in this historical and chronological review, these specialized hair follicles are of the utmost importance when attempting to achieve successful decolonization of the human nares. Also overlooked when discussing staphylococcal nasal carriage, is the presence of vellus hair follicles and sebaceous glands surrounding the vestibulum nasi that can harbor $S$. aureus [13].

\section{1889-1900-The First 11 Years of Data regarding Bacteria in Human Hair Follicles}

Two of the earliest mentions in the medical literature of microorganisms in infected hair follicles are from Park and Wright in 1889 [14] and Park for a second time in 1891 [15].

Park described a self-experiment conducted by German physician Max Bockhart, where Bockhart introduced a minute portion of "cultures of aureus and al- 
bus" on the skin of his own forearm, about the size of a silver dollar. It was reported that after "rubbing in" this inoculum, that within 24 hours pustules had formed with most of the pustules being perforated by hairs. After one week, only two pustules remained, but they then developed into large blisters and boils that caused recurrence of the pustules in the same area for up to three months. To this day, this infection of the hair follicle is known as Bockhart impetigo, which is a superficial follicular pustular eruption involving hairy areas [16] [17]. This self-experiment by Bockhart at the end of the $19^{\text {th }}$ century, appeared to support that the bacteria could in fact 1) colonize and 2) infect human hair follicles.

Park also described the self-experimentation of another German physician and pathologist Curt Schimmelbusch, who was an early developer of mechanical methods of sterilization and disinfection for surgical procedures [18]. Schimmelbusch rubbed into unbroken skin pure cultures of staphylococcus pyogenes aureus, and experienced pustules that broke out on his skin. As a pathologist, Schimmelbusch then 1) excised an area of the infected skin, 2) prepared and sectioned the biopsy, and 3) gram stained the skin sample with contrast. Upon microscopic examination of these samples, Schimmelbusch found "no injury to the skin tissues", but that the staphylococcus had followed the hair shaft down into its follicle, and there proliferated, and reported that the infection of the tissues proceeded from the infected follicle.

In 1895, Thomson and Hewlett made a series of observations about bacteria in the vestibulum nasi, while experimenting at King's College Hospital in London. In reporting their results, they stated the following: "The interior of the great majority of normal nasal cavities is perfectly aseptic. On the other hand, the vestibules of the nares, the vibrissae (nasal hairs) lining them, and all crusts formed there, are generally swarming with bacteria."

Thomson and Hewlett described:

1) "That in all bacterioscopic investigations of the nasal fossae, in all researches as to the action of the nasal mucus, \& c., a clear distinction must be made between the vestibule of the nose and the proper mucous cavity. The former is lined with skin, and is furnished with hairs and with sudoriferous and sebaceous glands; it is not part of the nose cavity proper, but only leads to it" and;

2) "In the dust and crusts of mucus and debris deposited among the vibrissae of healthy subjects microorganisms are never absent. They are rarely scanty in number; as a rule they are abundant." [19].

\section{4. (1900-1925) Early Physicians Come to a Broader Consensus Regarding the Microbiology of the Vestibulum Nasi}

In 1905, Shurly reported on Thomson and Hewlett's work on the bacteriology in the nose in his text A Treatise on diseases of the nose and throat, and similarly reported that other researchers had come to parallel conclusions [20]. In 1913, Allen defined an extensive protocol to clean the nasal vestibule and vibrissae 
with soap, sterile water and alcohol, along with then utilizing a sterile speculum to avoid the vibrissae when attempting to culture desired areas of the nose posterior to the vestibulum nasi [21]. This protocol was created to avoid cross contamination with bacterial species from the vibrissae, and sebaceous glands of the vestibule. In 1922, Phillips described the etiology of nasal furunculosis as caused by pyogenic staphylococcus, which gain access to the subcutaneous tissues of the nares through hair follicles (of the vibrissae) or the sudoriparous (sweat) glands [22]. Four years later, Herzig reported on the efficacy of a combination of the antiseptics Gentian Violet and Acriflavine, for the treatment of external bacterial infections, such as nasal furunculosis [23].

By 1925, experimental and observational data strongly pointed to the vestibulum nasi, and particularly the vibrissae as being most heavily colonized with $S$. aureus. These data presented a strong early signal as to where future treatments for nasal decolonization should be focused:

1) The skin of the vestibulum nasi;

2) The vibrissae of the vestibulum nasi; and

3) The sudoriparous glands of the vestibulum nasi.

\section{5. (1926-1944) Determination that $S$. aureus in the Vibrissae Follicles Can Spread to Other Areas of the Body-At the Dawn of the Age of Penicillin}

By the end of the 1920s, the landscape and understanding of $S$. aureus in the nose, its spread to other areas, and a potential treatment regimen with the new science of antibiotics began to emerge. In 1929, Fleming presented his famous data concerning the in vitro eradication of staphylococcal colonies harvested from the human nose in his seminal paper describing penicillin [24]. In 1930, Robert Keilty, an American ophthalmologist, determined that the source of staphylococcal infection of normal conjunctival sacs was from the nose [25] by way of the lacrimonasal duct. In 1932, the Norwegian dermatologist Danbolt showed that 35 patients with recurring nasal furunculosis had staphylococci with the same biochemical properties in the nose and in the infected hair follicle lesions in other areas. Danbolt suggested that the nasal staphylococcal colonization was accountable for the recurrent skin infection, representing autoinfection (i.e., infection from a source within the patient itself) [26].

In 1934, Davis conducted an early experiment concerning adequate masking of operating room staff during surgery. He found that for each individual in the operating suite, more staphylococci could be cultured from exhalation of the staff when only the mouth was masked, compared to the mouth and nose being masked [27]. In 1935 Conner, discussing the predisposing conditions to staphylococcal skin infections stated that, "When once the skin has been infected irritation of the hair follicles in which the organisms lurk predisposes to their active growth, and friction may determine the site of a boil or a carbuncle." [28].

In 1939, Gillespie, et al., demonstrated that there was an association between nasal carriage and skin carriage of $S$. aureus, [29] and also in 1939, Devenish and 
Miles reported the positive finding of $S$. aureus in the nose of two surgeons, one of which was reported to have far greater rates of surgical site infections. This surgeon was also found to have $S$. aureus colonization on his hands and frequently had punctured gloves [30]. One year later, there was a report of topical administration of aluminum chloride by Veach, who treated a group of patients with chronic Staphylococcal furunculosis in the nose with a $25 \%$ aqueous solution, producing a successful treatment outcome for all [31] [32].

In 1941, Delafield, et al., citing Fleming's work tested sulphathiazole and a sample of "newly purified" penicillin in snuff compounds, to attempt to eliminate nasal carriage of staphylococci [33]. Delafield, found a great reduction in nasal colonies that then returned to normal after the snuff therapy was discontinued. They stated the following based on this early human decolonization study:

"It may perhaps prove effective in curing nasal carriers of staphylococci or in reducing the number of vegetative organisms, so that the carrier becomes less dangerous as a source of infection to others."

Also in 1941, Thomas presented evidence that the nasal carriage of staphylococci could be reduced (not eliminated) by patients utilizing a "chemotherapeutic" snuff at an isolation hospital for diphtheria [34]. Thomas's snuff ingredients were sulpathiazole in magnesium carbonate. Thomas stated the following: "The snuff tends to produce a reduction in numbers of Staph. pyrogens rather than clearance which is in agreement with the findings of Delafield and Straker. However, even partial success, producing only a temporary clearing or a reduction in number of pathogens, is undoubtedly of considerable value in minimizing cross-infection in wards by reducing numbers of pathogens sprayed in the air.” Thomas continued, “... it might be beneficial, at least in resistant cases, to perform some-kind of nasal toilet immediately before giving the snuff."

In 1944, Miles, et al., stated after a human trial that: "The greater incidence of nasal carriage and the greater profusion of Staph. aureus found in the nose of carriers as compared with that on the skin of the wrist strongly suggests that the nose is the primary source of the cocci found on the hand... but since we have been able to show that nasal carriage is a relatively persistent state, it is clear that, even if the initial infection takes place in the skin, the nose subsequently becomes the chief source of Staph. aureus in any one person." [35]. In that same year, Taylor, et al., [36] reported the successful use of penicillin spray in the treatment of impetigo and furunculosis. Then in 1944, Gissane, et al., discussing the importance of wound antisepsis for healing, clearly pointed to the nose, as "a source from which a wound may become infected with Staphylococcus aureus" [37].

In 1945, Lovell removed sections of skin, incubated them for 6 hours in a moist chamber to permit the number of bacteria to increase. He then prepared, stained and studied the sections microscopically. Lovell reported that the "source of the resident flora in the skin" was the sebaceous glands [38] [39]. Also 
in 1945, Harkins described the early use of skin grafts to repair hernia incisions, and warned of "introduction of infection" from bacteria contained within the hair follicles of the graft [40].

Thus, by the end of World War II, it was the opinion of the vast majority of physicians and scientists that the hair follicles and sebaceous glands of the vestibulum nasi were the largest source of infective colonies of $S$. aureus. Physicians of that time had determined that $S$. aureus could not only self-infect at distant sites in a single person, but also could infect others. The further significant philosophy put forward in this time frame was that, 1) an antimicrobial in the nose could be used as a prophylactic to "diminish the number of existing pathogens in the nasal cavities" and; 2) An antimicrobial in the nose would have to be continued for a long time to effect any permanent cure.

\section{6. (1946-1970) Early Treatment Studies of Nasal Staphylococcus Carriage}

In 1947, Hobbs, et al., reported that patients receiving penicillin cream to both skin lesions and the nose of patients with sycosis barbae, harbored the identical type of bacteria, and that all but one patient healed to satisfaction with the penicillin cream. Four patients relapsed with the same serological type of staphylococcus, and two saw a recurrence with a different serological type. Hobbes suggested that, a relapse of sycosis barbae would most likely to occur based on reinfection of the skin from the nose [41]. In 1948, Moss, et al., deduced that skin carriage of $S$. aureus is dependent on nasal carriage in patients with normal skin. When Moss employed local penicillin treatment (to the nose), but not systemic treatment, the treatment reduced nasal $S$. aureus carriage from $97 \%$ to $37 \%$ and simultaneously reduced skin carriage from $57 \%$ to $38 \%$ after five days of treatment [42].

In 1950, Evans, et al. in an extensive study of the bacteriology of normal skin, showed that the bacterial count of the skin varies tremendously from individual to individual, and from time to time on the same individual. They noted that the colony count was much higher in areas well supplied with sebaceous glands, in further confirmation of the conclusions of Lovell in 1945 [43]. In 1953, describing the treatment for recurrent boils caused by staphylococci, Anning stated: "The bacterial population of the skin remains high for weeks after a boil has healed, and these efforts to reduce the staphylococcal flora must be continued for some time. Anning continued, "The nose of the patient is likely to be harboring numerous virulent staphylococci, although physical signs are absent" and suggested "Careful cleansing of the nasal vestibule with soap and water several times a day..." [44]. These suggestions of cleaning the nasal vestibule by Anning supported the previously mentioned cleaning protocols of Allen in 1913 [21] before taking bacterial samples posterior of the nares, and Thomas in 1941 [34] prior to the application of "chemotherapeutic" snuff to reduce Staphylococcal colonies in the nose.

In 1955, Gould conducted a study of multiple different topical antibiotics 
formulations in the nares, to attempt to prevent the infectivity of the staphylococcus carriers, by suppressing their staphylococcinasal carriage. This study was undertaken, as local measures of infection control in his hospital and "strict attention to aseptic technique" were not proving adequate to prevent staphylococcal infection. At the outset of the study, Gould stated: "Since the ultimate source of infection in both hospital and non-hospital cases must be the nares of carriers it is logical to attempt prevention by reducing the infectivity of the carriers, and this may be achieved by suppressing their staphylococci." Gould further believed that, "The local application of antibacterial agents may temporarily remove the organisms from the surface of the skin of the nares, but, as it is probable that the sweat and sebaceous glands are also colonized, total eradication may not be so easy to accomplish." [45].

In his study, Gould showed that it was necessary to employ concentrations up to 10,000 units per gram to the surface of the nares to penetrate into the sebaceous glands, and he continued the treatment for 14 days. He found that there was a decline in colony numbers in all patients during the time of antibiotic application and that seven days after the start of treatment no colonies could be cultured from 96 out of 124 carriers (77\%), and 69\% of all treated carriers were culture negative for two weeks or more after cessation of the therapy.

In his discussion, Gould stated that: "These experiments have shown that the topical application of $1 \%$ antibiotic cream was effective in suppressing Staph pyogenes in the human nose for an appreciably longer time than the cream was applied." Gould continued: "It is unlikely that the organism ceased to colonize the skin glands of the nares but rather that it was not present on the surface at the time of swabbing."

Gould concluded, "However, even if this was so it is still reasonable to suppose that the staphylococcus was not being passed to other sites on the body, nor disseminated into the air and dust, and therefore that the infectivity of these carriers was reduced." [45].

In 1959, Williams, et al., tested for post-operative wound sepsis in patients with staphylococcal nasal carriage. They found that upon admission to a male surgical ward in London, 38\% carried Staphylococcus aureus in their nose, and $13 \%$ carried penicillin-resistant strains [46].

Williams, et al., then reported:

1) The incidence of post-operative staphylococcal wound sepsis was $2 \%$ in 342 patients who were never nasal carriers of staphylococci and $7.1 \%$ in the 380 who carried at some time.

2) In about half the cases the sepsis was due to a staphylococcus of the same type as was found in the nose, and of patients who were nasal carriers of one or other of 10 apparently more virulent types, $35 \%$ had wound sepsis, in all cases due to the nasal type of Staphylococcus.

In 1963, Varga and White found a noteworthy relationship between staphylococci in both the nasal carriage and contaminated air samples, and that that nasal administration of oxacillin not only decreased nasal colonization, but also 
decreased the aerial colonies of $S$. aureus [47] [48]. These data came 13 years after Moss employed local penicillin treatment (to the nose), but not systemic treatment, and reduced nasal $S$. aureus carriage from $97 \%$ to $37 \%$ and simultaneously reduced skin carriage from $57 \%$ to $38 \%$ after five days of treatment [42].

In 1969, Montes and Wilborn found bacterial colonies present below the superficial cells of the Stratum corneum in skin samples and in the openings to the hair follicles, and associated with sebum [49]. They found that colony counts increased with occlusion of the skin, and visualized "numerous dividing cells" with electron microscopy.

In 1972 (one year after pseudomonic acid \{Mupirocin\} was purified), Selwyn and Ellis experimented on full thickness skin biopsies from a series of "sudden death" cadavers that had been stored under refrigeration for less than 24 hours. They found mean bacterial counts ranging from $4400 / \mathrm{cm}^{2}$ on the breast to $400,000 / \mathrm{cm}^{2}$ in the axillae. They further reported: [50]

1) An iodine preparation removed $95 \%$ of accessible organisms, and about $20 \%$ of Bacteria were protected by follicles, crevices, and lipids. Direct microscopic evidence of a relatively deep flora was obtained by Gram-staining fresh skin sections, and many bacteria were seen surprisingly deep in the larger hair follicles of un-incubated skin.

2) After incubation these bacteria could be seen exuding up the mouths of follicles, and more superficially located bacteria formed numerous colonies on incubated sections, even after thorough disinfection of the skin. Commensals in over $20 \%$ of people produced antibiotics against a wide range of pathogens.

Selwyn and Ellis concluded that the organisms were presumably protected from disinfection by lipids, especially at the mouths of follicles, or by overlying portions of the stratum corneum. They found no direct evidence that bacteria are normally found in deep layers of the epidermis outside pilosebaceous units.

Therefore, by the beginning of the 1970s there was now little doubt that:

1) The hidden source of up to $20 \%$ of the resident flora that re-colonize the skin is the colonized hair follicle, sebaceous glands, crevices, and lipids [50].

2) Skin carriage of $S$. aureus is heavily influenced by nasal carriage.

3) $1 \%$ (10,000 units per gram) topical antibiotics appear to be of a high enough concentration to penetrate into the sebaceous glands and hair follicles of the nares to lower colony counts.

4) Post-operative staphylococcal wound sepsis is higher in patients with staphylococcal nasal carriage, and a person with nasal carriage can shed substantial amounts of bacteria into the air.

5) Nasal administration of topical antibiotics not only decreased nasal colonization, but also decreased the aerial colonies of $S$. aureus, that can transfer to other sites on the same person, and other people.

\section{7. (1970-1985) Critical Information Gathered from the Original Mupirocin Studies against S. aureus}

In 1887, (five years after Ogston first isolated $S$. aureus (1882) from purulence in 
a human abscess) Baaderand Garre described the antibacterial activity associated with the bacteria Pseudomonas fluorescens harvested from a soil sample [51]. In 1889, the "antibiosis" phenomenon gained acceptance as being a substance produced by one micro-organism that inhibits another micro-organism [52]. It was not until 84 years later in 1971 that Fuller identified the "soil substance" of Baader and Garre as pseudomonic acid (Mupirocin), from Pseudomonas fluorescens [53]. In 1976, Sutherland, et al., presented data showing that pseudomonic acid carried antibacterial activity against gram-positive bacteria such as $S$. aureus, but not substantial activity against gram-negative enterobacteriacea or gram-positive enterococci. Sutherland also showed no cross-resistance with other antibiotics, and suggested a novel mechanism of action [54].

In 1978, Hughes and Mellows reported that pseudomonic acid was effective against $S$. aureus at concentrations of $0.05-0.5 \mu \mathrm{g} / \mathrm{ml}$, and that the MIC against $S$. aureus is $0.05 \mu \mathrm{g} / \mathrm{ml}$ and is bacteriostatic. They also reported that cells treated with pseudomonic acid within the MIC range, once transferred to fresh media, will spontaneously recover after several hours, and that higher concentrations are necessary for a bactericidal effect. They further described inhibition of protein synthesis by reversibly binding to isoleucyl transfer-RNA synthetase, as the novel mechanism of action for pseudomonic acid [55].

The first human study results for a pseudomonic acid preparation were published in August 1983 by Wuite, et al. who studied 46 patients referred to his clinic with pyogenic skin infections. The patients were given one or more tubes of a water miscible base containing $2 \%$ pseudomonic acid (20,000 units per gram) to apply to the infected area three times per day for five days, and returned to the clinic at day seven. In 43 of the 46 patients, the infection was reported as completely cleared [56].

Two months later, Dacre, et al., [57] decided during an outbreak of gentamicin-resistant MRSA in the urology clinic at the Whittington Hospital in London to employ the new $2 \%$ pseudomonic acid preparation, supplied to them from Beecham Pharmaceuticals. Dacre took swab samples from the nose, axillae and perineum of all patients and staff in the urology clinic. From these swabs, carriers of multi-drug resistant staphylococci were instructed to apply the $2 \%$ pseudomonic acid formulation 1) to the anterior nares and 2) to all other superficial sites where an $S$. aureus positive culture was obtained. In this patient population, once the treatment with pseudomonic acid was started, multi drug resistant staphylococci were not isolated from any patient site under treatment, and the staphylococci were eradicated in all cases. Two of the treated patients recolonized with the same strain and one patient with non-resistant colonies. At this time, Dacre suggested that the formulation of pseudomonic acid that was supplied by Beecham was not satisfactory for the nares, and irritated the nasal mucosa, because of the polyethylene glycol base (PEG) in which the pseudomonic acid was compounded.

Also in 1983, Casewell, citing three previous studies with Mupirocin in a polyethylene glycol base, discussed the safety of the new topical pseudomonic acid 
formulation, and stated: "We have doubts about polyethylene glycol as a base for the formulation of pseudomonic acid for sites such as the anterior nares." Casewell continued, "In vitro, polyethylene glycol is a fusogen, i.e., it fuses adjacent mammalian cells such as human fibroblasts and lymphocytes and it is used to produce hybridomas for monoclonal antibody production. It has also been suggested that in suppositories it may predispose to malignant change in rectal and vaginal mucosal cells." Casewell concluded, "Thus the side-effects noted by Dacre, et al., may well have been due to polyethylene glycol rather than to pseudomonic acid itself (in the nares). Beecham Pharmaceuticals have modified the formulation to make it more suitable for application to the anterior nares" [58]. This new formulation for the nares was $2 \%$ pseudomonic acid (20,000 units per gram) in paraffin.

Continuing in 1983, Chirife, et al., [59] reported on a series of antibacterial experiments with polyethylene glycol 400 (PEG 400) solutions, and found substantial antibacterial activity with PEG 400 alone. Chirife suggested that PEG 400 could be used in the preparation of "hydrophilic ointment bases incorporating a wide variety of therapeutic materials, including anti-bacterials, antibiotics, and steroids." Charife's study was conducted based on the results of Vaamonde, et al., (1982), who had previously shown that the polyethylene glycols (MW 200 and 400) have a significant inhibitory effect on $S$. aureus by themselves [60]. These early studies by Chirife and Vaamondecertainly suggest that a polyethylene glycol base was enhancing or acting synergistically with the pseudomonic acid formulation that was being utilized on the skin and the nose at that time of these early Mupirocin human trials.

Three years later (1985) at an international symposium in Amsterdam devoted to pseudomonic acid (now renamed Mupirocin), a plethora of early studies and data were presented on Mupirocin's antibacterial activity. At this symposium, data and results were presented on early 1) "nasal carriage" studies, 2) contact allergy and irritation" studies (with the new polyethylene glycol 400 formulation named Bactroban'), and 3) chemistry and metabolism studies [61] [62] [63] [64].

Later in 1985, Sutherland, et al., (as part of the Beecham Pharmaceuticals Research Division) published a large compilation of in vitro data concerning the antimicrobial activity of Mupirocin on clinical strains [65]. Sutherland stated that Mupirocin showed "a high level of activity against staphylococci and streptococci, and against certain gram-negative bacteria, including Haemophilus influenza and Neisseria gonorrhoeae." Sutherland further stated that, "Nearly all clinical isolates of Staphylococcus aureus and Staphylococcus epidermidis, including multiply resistant strains, were susceptible (Mupirocin MIC, $\leq 0.5$ $\mu \mathrm{g} / \mathrm{ml}) \ldots$...and that the activity of Mupirocin was not greatly influenced by inoculum size, but was significantly enhanced in acid medium." Finally, Sutherland reported that minimum bactericidal concentrations (MBCs) were 8- to 32fold higher than MICs, and the antibiotic demonstrated a slow bactericidal action in time-kill tests, resulting in $90 \%$ to $99 \%$ killing after $24 \mathrm{hrs}$ at $37^{\circ} \mathrm{C}$. 
Also in 1985, Wuite, et al., reported on a number of Phase II studies with the $2 \%$ polyethylene glycol formulation of Mupirocin and concluded that Mupirocin in polyethylene glycol proved highly effective in the treatment of patients with minor pyogenic skin infections, and Casewell, et al., confirmed the bacteriostatic nature of Mupirocin with prolonged exposure producing superior killing kinetics, and generating sterile cultures at $1 \mu \mathrm{g} / \mathrm{ml}$ at 120 hours (five days) [66]. Importantly, before the 120-hour mark, regrowth of surviving colonies would occur at $0.25 \mu \mathrm{g} / \mathrm{ml}$ without the presence of mutants, in an inoculum of $10^{6} \mathrm{CFU}$. With higher inoculums of $10^{9} \mathrm{CFU}$, resistant variables (on agar) were found at 2 $\mu \mathrm{g} / \mathrm{ml}$ that had stable MICs at $1-4 \mu \mathrm{g} / \mathrm{ml}$ Mupirocin, as compared to $0.03-0.06$ $\mu \mathrm{g} / \mathrm{ml}$ for the original inoculum. Correspondingly, these colonies also showed "striking orange/yellow" pigmentation, which was then lost on sub-culture, most likely due to the extra production of $\beta$-carotene. Casewell concluded that this level of resistance "may not be significant" as the topical $2 \%$ formulation of $\mathrm{Mu}$ pirocin contains $20,000 \mu \mathrm{g} / \mathrm{ml}$ of the antibiotic. See Table 1.

Finally in 1985, the United States Food and Drug Administration approved a new "Nasal Formulation" of Mupirocin in Paraffin, indicated for "the eradication of nasal colonization with methicillin-resistant Staphylococcus aureus

Table 1. In Vitro $S$. aureus data.

\begin{tabular}{|c|c|c|c|c|c|}
\hline Year & $\begin{array}{c}\text { Mupirocin } \\
\text { Concentration }\end{array}$ & Bacteriostatic & Bactericidal & Observations & Ref \\
\hline 1978 & $0.05 \mu \mathrm{g} / \mathrm{ml}$ & Yes & & $\begin{array}{l}\text { Cells treated with pseudomonic acid within the MIC range, } \\
\text { once transferred to fresh media, will spontaneously recover after } \\
\text { several hours, and that higher concentrations are necessary for a } \\
\text { bactericidal effect. }\end{array}$ & [55] \\
\hline 1985 & MIC, $\leq 0.5 \mu \mathrm{g} / \mathrm{ml}$ & Yes & & $\begin{array}{l}\text { Nearly all clinical isolates of Staphylococcus aureus and } \\
\text { Staphylococcus epidermidis, including multiply resistant strains, } \\
\text { were susceptible (Mupirocin MIC, } \leq 0.5 \mu \mathrm{g} / \mathrm{ml} \text { ) ....and the } \\
\text { activity of Mupirocin was not greatly influenced by inoculum } \\
\text { size, but was significantly enhanced in acid medium." } \\
\text { Minimum bactericidal concentrations were } 8 \text { - to } 32 \text {-fold higher } \\
\text { than MICs, and the antibiotic demonstrated a slow bactericidal } \\
\text { action in time-kill tests, resulting in } 90 \text { to } 99 \% \text { killing after } 24 \\
\text { hrs. incubatedat } 37^{\circ} \mathrm{C} \text {. }\end{array}$ & [65] \\
\hline 1985 & $\begin{array}{c}1 \mu \mathrm{g} / \mathrm{ml} \text { at } 120 \\
\text { hours }\end{array}$ & & Yes & $\begin{array}{l}\text { Before the } 120 \text {-hour mark, regrowth of surviving colonies would } \\
\text { occur at } 0.25 \mu \mathrm{g} / \mathrm{ml} \text { without the presence of mutants, in an } \\
\text { inoculum of } 10^{6} \mathrm{CFU} \text {. } \\
\text { With higher inoculums of } 10^{9} \mathrm{CFU} \text {, resistant variables (on agar) } \\
\text { were found at } 2 \mu \mathrm{g} / \mathrm{ml} \text { that had stable } \mathrm{MICs} \text { at } 1-4 \mu \mathrm{g} / \mathrm{ml} \\
\text { Mupirocin, as compared to } 0.03-0.06 \mu \mathrm{g} / \mathrm{ml} \text { for the } \\
\text { original inoculum. } \\
\text { Colonies also showed "striking orange/yellow" pigmentation, } \\
\text { which was then lost on sub-culture, most likely due to the extra } \\
\text { production of } \beta \text {-carotene. } \\
\text { Casewell concluded that this level of resistance "may not be } \\
\text { significant" as the topical } 2 \% \text { formulation of Mupirocin contains } \\
20,000 \mu \mathrm{g} / \mathrm{ml} \text { of the antibiotic. }\end{array}$ & [66] \\
\hline
\end{tabular}


(MRSA) in adult and pediatric patients" that had no contraindications for use on nasal or mucosal tissues.

\section{New Mupirocin Formulations in Human Studies for Nasal Decolonization and Wounds}

In 1986, Casewell and Hill conducted the first moderately sized controlled trial, with the newly approved formulation of $2 \%$ Mupirocin in white soft paraffin. Thirty-six subjects that tested positive for stable nasal carriage with $\mathcal{S}$. aureus were recruited into the study, and 18 of them were given Mupirocin and 18 given the identical paraffin base without Mupirocin [67]. All participants were instructed to apply an amount of paraffin "the size of a match head" four times/ day (q.i.d.) for five days and "to squeeze their nose between finger and thumb after each application to ensure even distribution." Culture swabs were examined after one, four, eight and 20 applications. Casewell and Hill reported that all Mupirocin treated patients had $S$. aureus carriage eliminated from their nares. None of the patients were shown to eliminate nasal carriage in the control vehicle arm. Three weeks after the treatment phase, three patients regained $S$. aureus in the nares, without an increase in the MIC to Mupirocin. Also of note, in 1986, the Hospital Infection Society and the British Society for Antimicrobial Chemotherapy recommended treatment of nasal carriers of MRSA with Mupirocin in paraffin applied to the anterior nares three times/day (t.i.d.) for at least five days [68].

In 1987 , a new cream preparation of $2 \%$ Mupirocin was approved by the FDA for secondarily infected traumatic skin lesions. This formulation contained benzyl alcohol, cetyl alcohol, phenoxy-ethanol, and stearyl alcohol, as preservatives and emulsifiers. As with the polyethylene glycol base for the Mupirocin ointment (FDA approved for the topical treatment of impetigo), the hydrocarbon alcohols in the cream formulation all can have significant synergistic effects with the Mupirocin against $S$. aureus, but are (a) incompatible with and (b) not FDA approved for nasal or mucosal tissues [69]-[74]. This incompatibility of the hydrocarbon alcohol cream formulation stems from erythema, edema and contact irritation on nasal and mucosal tissues caused with the hydrocarbon alcohols in the base [75].

By the end of 1987, the data concerning Mupirocin was becoming increasingly clear. The data described:

1) The MIC in vitro against $S$. aureus is $0.05 \mu \mathrm{g} / \mathrm{ml}$ of pseudomonic acid, and it is a bacteriostatic antibiotic,

2)The polyethylene glycol base was most likely acting synergistically with pseudomonic acid, and was not satisfactory for the nares, as it was highly irritating to the nasal mucosa,

3) Studies done to date showed Mupirocin in a polyethylene glycol base to be effective in treating primary skin infections with clinical cure or improvement approaching $95 \%$,

4) A $2 \%$ Mupirocin cream formulation was also approved in a base of syner- 
gistic preservative and emulsifier alcohols, targeted for use in small infected wounds,

5) In vitro studies reported that MBCs were 8- to 32-fold higher than MICs, and Mupirocin demonstrated a slow bactericidal action,

6) Mupirocin was not able to generate sterile cultures in vitro at $1 \mu \mathrm{g} / \mathrm{ml}$ until 120 hours (five days), and before the 120-hour mark, regrowth of surviving colonies would occur at $0.25 \mu \mathrm{g} / \mathrm{ml}$ without the presence of mutants, in an inoculum of $10^{6} \mathrm{CFU}$. In higher inoculums of $10^{9} \mathrm{CFU}$, resistant variables (on agar) were found at $2 \mu \mathrm{g} / \mathrm{ml}$ that had stable MICs at $1-4 \mu \mathrm{g} / \mathrm{ml}$ Mupirocin, as compared to $0.03-0.06 \mu \mathrm{g} / \mathrm{ml}$ for the original inoculum.

\section{9. (1988-2010) Mupiricin (Paraffin) Influential Nasal Decolonization Studies}

In 1988, Hill, et al., reported on a hospital outbreak of MRSA where 40 patients and 32 hospital staff that tested as stable nasal carriers of MRSA received topical application of 2\% Mupirocin in paraffin to their anterior nares for t.i.d. for five days [76]. Hill reported that nasal carriage was eliminated in all treated patients and staff, usually within the first 48 hours of treatment. Four patients recolonized within two weeks after Mupirocin therapy. Immediately after the Mupirocin therapy was completed, the number of patients with MRSA isolated from wrists fell from 16 to three.

Also in1989, Bulanda, et al., treated 69 volunteers with either persistent, intermittent or transient $S$. aureus carriage in the anterior nares with Mupirocin in paraffin t.i.d. for five days [77]. The treatment eradicated $S$. aureus from 67 of the 69 participants when tested four days after the last dose. At two weeks post therapy, approximately $40 \%$ of the patients had recolonized with $S$. aureus in the nose.

In 1991, Regan, et al., treated 68 patients with stable $S$. aureus carriage, in a double-blind, placebo-controlled randomized trial [78]. Participants received either Mupirocin in paraffin, or placebo intra-nasally twice daily (B.I.D.) for five days. Regan measured cultures of the hands and nares at baseline and 72 hours after therapy. They reported that the proportion of hand cultures positive for $S$. aureus in the Mupirocin group after therapy was significantly lower than in the placebo group (2.9\% compared with 57.6\%). Regan concluded that when applied intra-nasally twice daily for five days, Mupirocin in paraffin has a corresponding effect on hand carriage at 72 hours after therapy.

Also in 1991, Redhead, et al., reported on a clinical study conducted at 102 hospitals in the UK and Ireland, where 1510 subjects were treated with Bactroban nasal ointment (paraffin base) during hospital outbreaks of MRSA. The Mupirocin was applied to "most patients" two or three times daily to both anterior nares for three to eight days. Redhead reported that of 766 assessable subjects, nasal carriage of $S$. aureus was cleared in 744 (97.1\%). These results established that Bactroban nasal was a highly effective therapy for eradication of nasal carriage of $S$. aureus, including MRSA [79]. 
In 1992, B. Doebbeling, et al., [80] reported on a multicenter double-blind study of study of 339 hospital staff that were tested as stable carriers of $S$. aureus, and received either Mupirocin nasal, or placebo b.i.d. for five days. 91\% of the evaluable subjects saw nasal carriage elimination post treatment (vs $6 \%$ for placebo) and at four weeks post therapy.

Also in 1992, Scully, et al., reported on a placebo-controlled, double-blind study of Mupirocin in paraffin for nasal eradication of MSSA and MRSA. [81] Seventy subjects completed therapy and had the required follow-up to be considered assessable. Thirty-four subjects received Mupirocin and 36 subjects the placebo ointment. In the therapy phase, $1 \mathrm{~cm}$ of study ointment (Mupirocin or placebo) was placed on a cotton swab and applied inside each nostril twice daily for five days. After application, the nostrils were massaged externally between the fingers for one minute to ensure even application. Follow-up cultures were obtained between 24 and 72 hours after the last dose and one, two and four weeks after treatment. All except one strain were highly susceptible to Mupirocin. $90 \%$ of the staphylococci were inhibited by $0.125 \mathrm{mg} / \mathrm{L}$ or less of Mupirocin. Scully reported $74 \%$ nasal eradication in the Mupirocin arm after five days, vs $3 \%$ in the placebo arm. This is the second study showing lower eradication success (74\%) in the nares with Mupirocin (paraffin) application at b.i.d. for five days.

In 1994, B. N. Doebbeling reported on the pooled results of six double-blind, randomized, placebo-controlled clinical trials in the United States to evaluate the elimination of $S$. aureus carriage in healthcare workers with Mupirocin nasal [82]. Hand cultures were also performed at one center. All six centers followed a common protocol, and $1 \mathrm{~cm}$ of study ointment (Mupirocin or placebo) was placed on a cotton swab and applied inside each nostril b.i.d. for five days. The primary endpoint of the study was elimination of $S$. aureus from the nares at 48 96 hrs. post-therapy. The overall eradication rate for the active Mupirocin arm was $91 \%$ vs $6 \%$ in the placebo arm. At the study site that also tested hand carriage, 3\% reported positive for $S$. aureus in the Mupirocin arm immediately post-therapy, vs $58 \%$ in the placebo arm.

In 1995, C. Fernandez, et al., reported on a nasal decolonization study with 68 health care workers that was a double-blind, and randomized to receive either Mupirocin nasal or placebo, b.i.d. for five days [83]. Fernandez found that $\mathrm{Mu}$ pirocin eliminated nasal carriage with Staphylococcus aureus in $86.7 \%$ subjects by the end of therapy compared to $9.4 \%$ subjects at the end of treatment with placebo $(P<0.001)$.

Van Rijen, et al., published systematic review of Staphylococcus aureus infections in surgical patients with nasal carriage (2002-06), and collected data on a large series of studies meeting a criteria for an $S$. aureus nasal eradication component, utilizing Mupirocin nasal for a b.i.d. for five days regimen [84].

> They highlighted that nasal carriage is only eliminated in $\sim 80 \%$ of patients treated with Mupirocin and $30 \%$ in those treated with placebo, when following the b.i.d. regimen. 
Van Rijen cited three studies [85] [86] [87] that reported 82\% (2002), 83\% (2002), 81.5\% (2006) successful nasal eradication in the studies.

In 2010, Bode, et al., reported on a randomized, double-blind, placebo-controlled, multicenter trial that treated MSSA patients with Mupirocin nasal ointment and chlorhexidine soap, to assess any reduction in hospital-associated MSSA infection [88]. Bode et al. reported that in their study, 1,270 nasal swabs from 1251 patients were positive for MSSA.

$>917$ of the patients were enrolled in the intention-to-treat analysis, of whom $808(88.1 \%)$ underwent a surgical procedure, and all the $S$. aureus strains were susceptible to methicillin and Mupirocin.

The rate of $S$. aureus infection was $3.4 \%$ in the Mupirocin-chlorhexidine group, as compared with $7.7 \%$ in the placebo group and the effect of Mupirocin-chlorhexidine treatment was most pronounced for deep surgical-site infections.

With these results, Bode, et al., concluded that the number of surgical-site MSSA infections acquired in the hospital can be reduced by decolonizing of nasal carriers of $S$. aureus on admission.

\section{Conclusions (1986-2010)}

20 years of clinical studies were examined, highlighting a definite emerging pattern: See Table 2.

1) The single early Mupirocin paraffin study with q.i.d. treatment resulted in $100 \%$ efficacy.

2) Early studies with t.i.d. therapy resulted in nearly $97 \%$ plus efficacy.

3) The transition to b.i.d. therapy in the 1990s, resulted in a decrease in efficacy to an average of $86 \%$.

Table 2. Efficacy chart for MRSA Nasal Decolonization studies with Mupirocin in paraffin 1986-2006.

\begin{tabular}{cccccc}
\hline Year & $\begin{array}{c}\text { Application } \\
\text { Per Day }\end{array}$ & $\begin{array}{c}\text { Number of } \\
\text { Days }\end{array}$ & $\begin{array}{c}\text { Elimination } \\
\text { after trial }\end{array}$ & Recolonization & Reference \\
\hline 1986 & $4 \times$ per Day & 5 Days & $100 \%$ & $16 \%$ at 3 weeks & {$[67]$} \\
1988 & $3 \times$ per Day & 5 Days & $100 \%$ & $6 \%$ at 2 weeks & {$[76]$} \\
1989 & $3 \times$ per Day & 5 Days & $97 \%$ & $40 \%$ at 2 weeks & {$[77]$} \\
1991 & $2 \times-3 \times$ per day & 3 -8 days & $97 \%$ & Unknown & [79] \\
1992 & $2 \times$ per day & 5 days & $91 \%$ & Unknown & {$[80]$} \\
1992 & $2 \times$ per day & 5 days & $74 \%$ & $22 \%$ at 4 weeks & {$[81]$} \\
1994 & $2 \times$ per day & 5 days & $91 \%$ & $26 \%$ at 4 weeks & {$[82]$} \\
1995 & $2 \times$ per day & 5 days & $86.7 \%$ & $43 \%$ at 4 weeks & {$[83]$} \\
2002 & $2 \times$ per day & 5 days & $82 \%$ & Unknown & {$[85]$} \\
2002 & $2 \times$ per day & 5 days & $83 \%$ & Unknown & {$[86]$} \\
2006 & $2 \times$ per day & 5 days & $81 \%$ & Unknown & {$[87]$} \\
\hline
\end{tabular}


4) Ten years later, Mupirocin paraffin efficacy decreased again at b.i.d. therapy to $82 \%$.

5) This researcher has not been able to find a single reference discussing that the fact that the new paraffin base of Mupirocin did not have any "assistance" in treating $S$. aureus colonization, as is the case with a synergistic polyethylene glycol or hydrocarbon-alcohol base.

6) There has never been a Mupirocin nasal decolonization study that has not reported recolonization of some measure within a $2-3$ week period.

The current regimens for Mupirocin decolonization are; 1) NHS UK: Mupirocin 2\% nasal 2 to 3 times per day. No mention of number of treatment days [89] and 2) United States/FDA: Mupirocin 2\% Nasal 2 times per day for five days [90].

\section{Testing the Efficacy of Different Commercial Mupirocin Formulations Agaiunst Multiple Strains of HA-MRSA and CA-MRSA}

For the purpose of these experiments, two null hypotheses were formulated to test for synergy between commercial Mupirocinointment and cream formulations compared to Mupirocin nasal (compounded in paraffin).

Null hypothesis 1: $\mu_{2}-\mu_{1}=0$ when MRSA strains, growth and commercial Mupirocin formulations are identical.

Null hypothesis 2: $\mu_{3}-\mu_{2}=0$ when MRSA strains, growth and commercial Mupirocin formulations are identical.

1) $\mu_{1}$ is the size of the colony inhibition zone with the commercial Mupirocin nasal formulation in Paraffin;

2) $\mu_{2}$ is the is the size of the colony inhibition zone with the commercial Mupirocin benzyl and phenoxy-ethanol cream formulation;

3) $\mu_{3}$ is the is the size of the colony inhibition zone with the commercial $\mathrm{Mu}$ pirocinin Polyethylene Glycol (PEG) ointment formulation;

- $\mu_{2}-\mu_{1}=0$ will show that the compounding of Mupirocin with a benzyl and phenoxy-ethanol cream formulation produces no beneficial effect beyond Mupirocin nasal in paraffin alone, and the null hypothesis stands.

- $\mu_{2}-\mu_{1}>0$ will show that the compounding of Mupirocin with a benzyl and phenoxy-ethanol cream formulation produces a measurable potentiation and beneficial effect of the Mupirocin beyond the paraffin.

- $\mu_{3}-\mu_{2}=0$ will show that the compounding of Mupirocin with a PEG ointment formulation produces no beneficial effect beyond Mupirocin in a benzyl and phenoxy-ethanol cream formulation.

- $\mu_{3}-\mu_{2}>0$ will show that the compounding of Mupirocin with a PEG ointment formulation produces a measurable potentiation and beneficial effect beyond Mupirocin in a benzyl and phenoxy-ethanol cream formulation.

\subsection{Materials and Methods-Strain Resurrection and Glycerol Stock Generation}

Staphylococcus aureus freeze-dried pellets (strains: BAA-41, BAA-1680, BAA- 
1708 and BAA-1556) were dissolved in $5 \mathrm{ml}$ of Tryptic Soy Broth (animal-free, Mediatech) and incubated shaking at $37^{\circ} \mathrm{C}$ for $16-18$ h overnight. Glycerol stocks were generated by mixing subsequent bacterial cultures 1:1 with $2 \times$ Cyropreservation Solution [65\% glycerol (w/v), 0.1 $\mathrm{M} \mathrm{MgSO}_{4}$, and $0.025 \mathrm{M}$ Tris- $\mathrm{HCl} \mathrm{pH}$ 8.0] and stored at $-80^{\circ} \mathrm{C}$. Data for SCCmec type, Clone type, PVL toxin and MupA gene garnered from American Type Culture Collection (www.atcc.org).

\subsection{Bacterial Growth}

$S$. aureus strains were streaked from glycerol stocks onto Mueller Hinton HiVeg Agar No. 2 (HiMedia) plates and a single colony was inoculated into $10 \mathrm{ml}$ of Tryptic Soy Broth and incubated shaking at $37^{\circ} \mathrm{C}$ for $16-18 \mathrm{~h}$ overnight. The next day the cultures were then back diluted into $20 \mathrm{ml}$ of fresh Tryptic Soy Broth and incubated shaking at $37^{\circ} \mathrm{C}$ to OD600 $=0.5-1.0$. The strains were then examined for biofilm formation and antimicrobial susceptibility.

\subsection{Biofilm Assay}

A sample of each bacterial culture was streaked on Congo Red Agar plates [Brain Heart Infusion Broth (Criterion), 2.5\% sucrose, 0.08\% congo red, 2\% agar), in triplicate, and incubated overnight at $37^{\circ} \mathrm{C}$ for $16-18 \mathrm{~h}$ to examine the biofilm formation capabilities of each strain [91] [92] [93].

\subsection{MIC Assay}

$500 \mathrm{ul}$ of each bacterial culture was plated onto Mueller Hinton HiVeg Agar No. 2 or Congo Red Agar plates $(150 \mathrm{~mm} \times 15 \mathrm{~mm})$, in triplicate, using a sterile cotton tip applicator to generate a complete bacterial lawn. Antimicrobial susceptibility test strips were then applied to the plates to measure MIC (E-test, bioMerieux) and incubated overnight at $37^{\circ} \mathrm{C}$ for 16 - $18 \mathrm{~h}$. Mupirocin (cat\# 516348) strips were used on each plate:

\subsection{Topical Assay}

Topical antibiotic commercial formulations $(\sim 2 \mathrm{~cm}$ discs $)$ of Mupirocin nasal $2 \%(20,000 \mu \mathrm{g} / \mathrm{ml}$ in Paraffin), Mupirocin cream 2\% $(20,000 \mu \mathrm{g} / \mathrm{ml}$ in benzyl and phenoxy-ethanolemulsion) and Mupirocin Ointment $2 \%(20,000 \mu \mathrm{g} / \mathrm{ml}$ in Polyethylene Glycol base) were applied to plates and incubated at $37^{\circ} \mathrm{C}$ for $16-18$ $\mathrm{h}$ overnight. All pictures of topical antibiotics captured with $300 \times$ digital microscope at 1) a set distance and 2) 200× magnification.

\subsection{Data}

Each MRSA strain tested showed a substantial synergy between the Mupirocin and both the 1) commercial benzyl and phenoxy-ethanol cream emulsion and 2) PEG ointment base, well beyond what is seen with the nasal paraffin base (See Figures 1-4). Also depicted is the fact that in all four MRSA strains, the PEG base had greater synergy and potentiation against both biofilm production and colony formation than did the benzyl and phenoxy-ethanol cream emulsion 


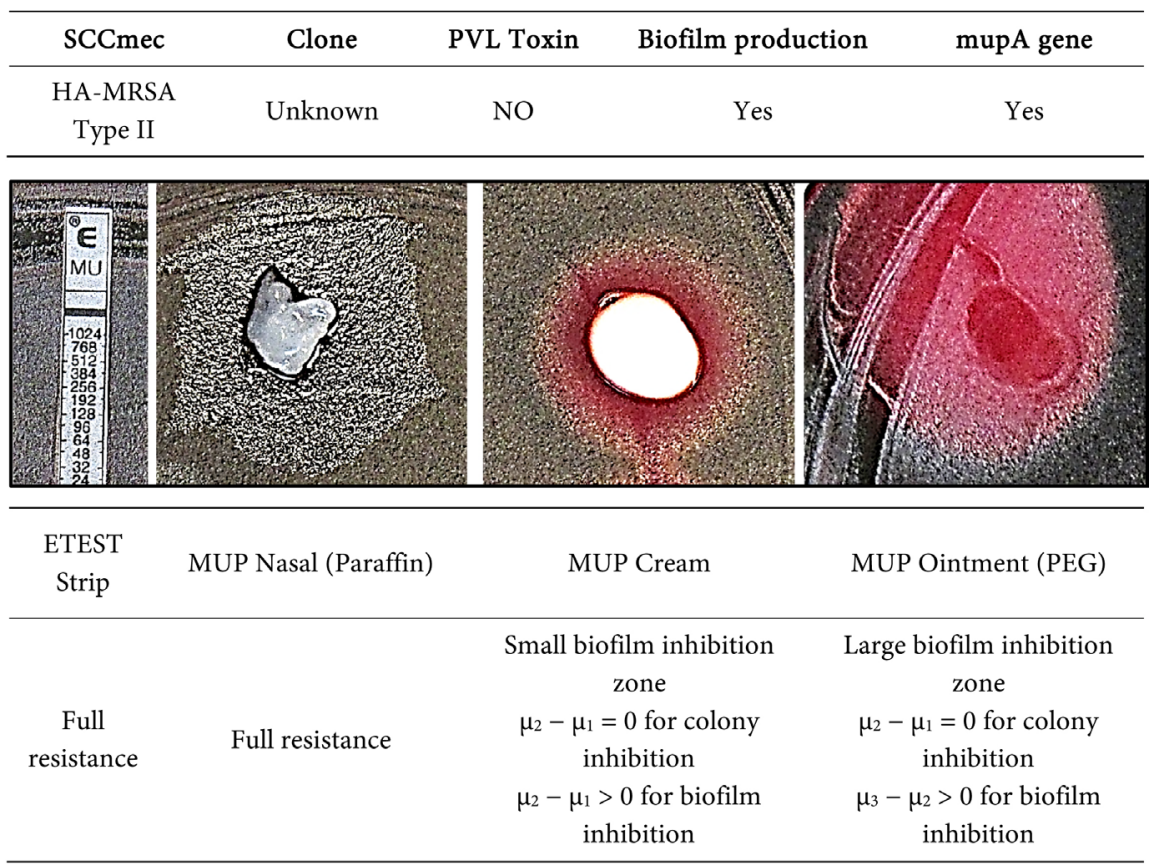

Figure 1. Strain BAA-1708.

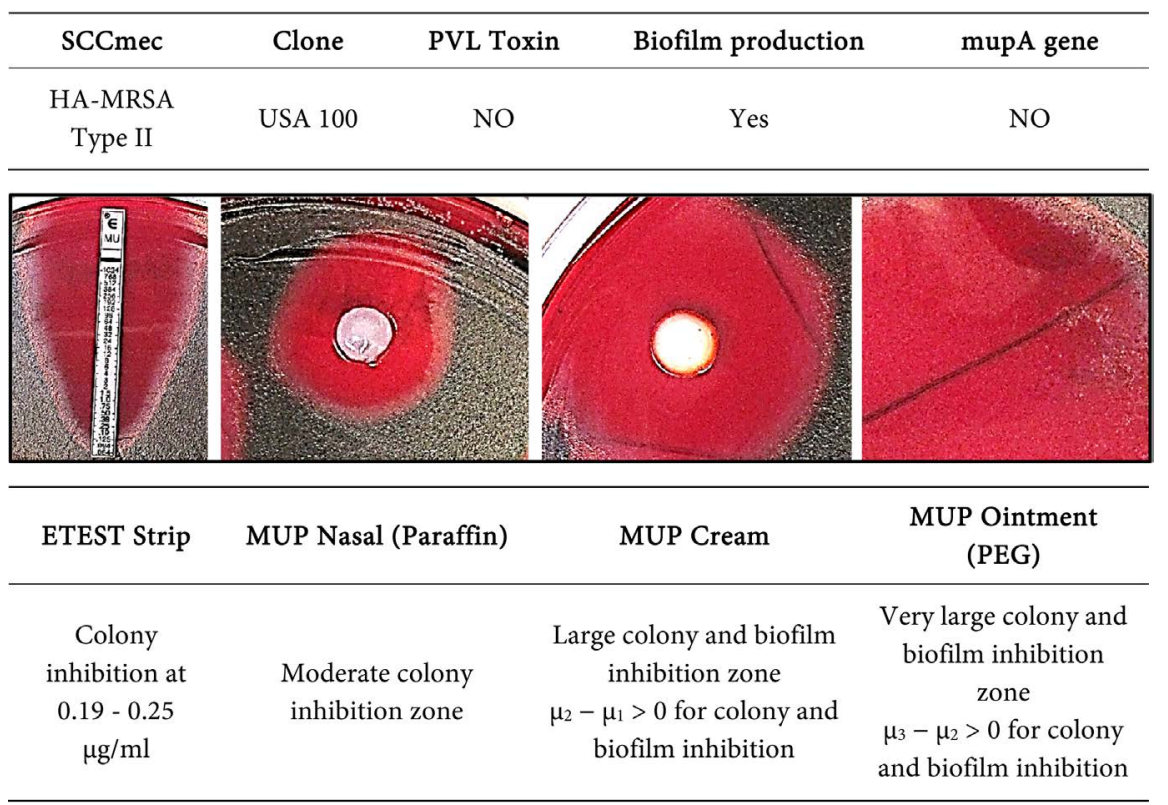

Figure 2. Strain BAA 41.

base. These data would appear to confirm the positive antibacterial data concerning the (base) ingredients of both commercial alternatives to Mupirocin nasal formulated in paraffin [59] [60] and [69]-[75]. To this researcher's knowledge, the publication of direct comparator data such as this, has not been presented before.

This data would further appear to indicate that cross-comparison of MRSA susceptibility data and clinical outcomes cannot be correlated between the different commercial formulations of Mupirocin. Further examination needs to be 


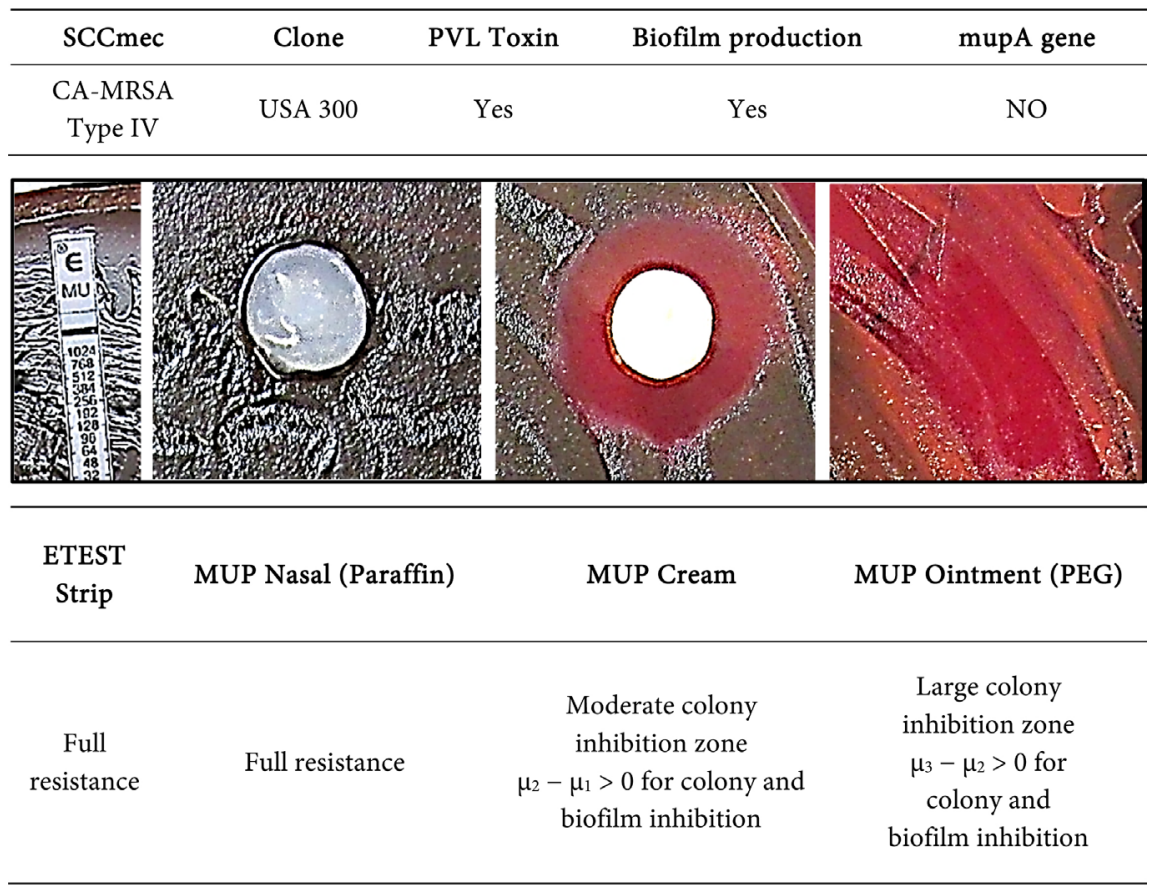

Figure 3. Strain BAA 1556.

\begin{tabular}{ccccc}
\hline SCCmec & Clone & PVL Toxin & Biofilm production & mupA gene \\
\hline $\begin{array}{c}\text { CA-MRSA } \\
\text { Type IVa }\end{array}$ & USA 300 & Yes & Yes & NO \\
\hline & & & & \\
\hline
\end{tabular}

Figure 4. Strain BAA 1680.

done with impetigo and wound applications of the MupirocinPEG ointment base and cream emulsion, as they appear to confer a far greater antibacterial and anti-biofilm effect on MRSA, than the Nasal Paraffin formulation. Unfortunately, neither the cream emulsion nor the PEG ointment can be utilized in the nose because of significant danger to and irritation of the nasal mucosal tissues [57] [58] [75]. 


\section{2. (1984-2014) Modern Hair Follicle Studies, and How They Relate to Contemporary Nasal Decolonization Efforts}

In 1984, Kearney, et al., reported results on a human cadaver skin biopsy study [94] and fundamentally confirmed the work of Selwyn and Ellis in 1972. They reported that Propionibacteria and Staphylococci are found heterogeneously in high densities in all parts of the follicular canal. They concluded complete skin disinfection would "require the penetration of disinfectant throughout the whole pilosebaceous canal" and further stated "This applies not only to prophylactic skin disinfection for surgical or aseptic manipulations but also to the use of topical antibiotics in disease states such as acne vulgaris."

In 2001 and 2005, it was determined that sebum production follows a defined circadian pattern, in a 24 hour cycle [95] [96]. Human sebum production peaks at 13:00 hrs and troughs from 23:00-06:00. This suggests that there may be "optimum times" for attempting to get topical antimicrobial formulations into the hair follicles of the vibrissae.

In 2005, Vogt et al. wrote a paper discussing follicular targeting, as a "Promising Tool in Selective Dermatotherapy" for drug delivery [97]. In this report, she stated, "Besides these anatomic characteristics, a wide variety of factors including the drug carrier system, the formulation, temperature, humidity, and pretreatment techniques of the skin influence the degree of drug deposition in the pilosebaceous unit." In 2006, Lademann et al., studying Nano-particle penetration into hair follicles, suggested that the follicle acts as a geared pump for nanoparticles, if their size is comparable with the thickness of the hair shaft dandruff [98]. Lademann concluded; that "the reservoir of the hair follicles is a long-term reservoir, because depletion can only occur during slow processes-by penetration into deeper tissue layers or by flowing out with the sebum production." In 2007, Lademann presented in vitro data that showed that particle penetration increased into hair follicles when massage was applied [99]. He stated that this encourages hair movement, which in vivo occurs physiologically.

In 2010, Broeke-Smits et al. performed the first series of experiments attempting to "define" the ecological niche in the nose for $S$. aureus to the Vestibulum nasi and actually named the "Hair Follicles" in the title of their paper [100]. After swabs were taken from the noses of 37 human cadavers, the nose was removed and vertically dissected. Tissue sections of 4 microns thick were cut and mounted on glass microscope slides, and were further prepared with Anti-SpA that showed positive staining for $S$. aureus. In this study, Broeke-Smits found positive $S$. aureus cultures in nine out of 37 nose swabs. In the microscopy slides, $S$. aureus was found in the Vestibulum nasi only. No bacteria were detected in the ciliated mucosa covering the major part of the nose or in its associated serous glands.

They further reported: 1) "The majority of the bacteria were found within the cornified layer of the stratified squamous epithelium and in the associated kera- 
tin and mucous debris within the vestibulum" 2) "To our surprise, in six out of nine culture-positive noses the bacteria were also detected in the outer portion of the hair follicle shafts" and 3) "In two out of six hair follicle-positive noses, bacteria were detected in deeper parts of the hair follicle”. Broeke-Smits postulated that the "occurrence of relapses after decolonization and the difficulties of decolonizing some individuals might be related to the inaccessibility of $S$. aureus deeply embedded in hair follicles. It might be worthwhile to reconsider the method of delivering Mupirocin, as it is questionable whether hairs and follicles will be efficiently decontaminated."

In 2011, Lange-Asschenfeldt, et al., utilizing 1) differential tape stripping, 2) cyanoacrylate skin surface biopsies and 3) mapping of hair follicles, showed that $85 \%$ of the bacteria were found within the first six corneocyte layers and roughly $25 \%$ of the cutaneous bacterial population were localized within the hair follicles on the forearms of study participants [101]. They concluded a) That "the skin appendages "form a protected microbial reservoir" and; b) That "this understanding might be of importance for the development of antiseptic substances that should access the hair follicles to prevent the fast repopulation of bacteria derived from this reservoir."

In 2012, another part of the "hair follicle" conundrum was presented by the work of Matard et al., who studied hair follicles in folliculitis decalvans, which is an inflammation of the hair follicle that leads to pustules, erosions, crusts, and is almost never devoid of $S$. aureus. [102] Matard reported on the first evidence of the presence of bacterial biofilms in the infra infundibular (deeper portion) of human scalp hair follicles, (in both folliculitis decalvans patients and in healthy subjects), utilizing field emission scanning electron microscopy and laser confocal scanning microscopy.

In 2013, Alexeyev introduced a new table codifying bacterial population sampling methods that included 1) swab, 2) scrape 3) cyanoacrylate and 4) biopsy [103]. He stated that the "swab method" only identifies bacterial colonies at the level of the superficial stratum corneum. This suggests that conventional nasal culture techniques are wholly inadequate to determine colonization and decolonization status in the nares. This further suggests that most (if not all) prior nasal decolonization studies would show far lower "actual" decolonization rates, if any of the other post-treatment sampling methods (with greater accuracy) were employed in the data collection after the therapy.

In 2014, Jans et al. presented further evidence in infected folliculitis patients of "large biofilm-like macro colonies in the deep part of the hair follicle [104]. Also in 2014, Ulmer et al. stated that the hair follicles could be used as a reservoir for topically applied substances, and that "non-particular" topicals could be detected for up to four days in a follicle after delivery [105]. Ulmer also stated that liposomes could also represent an effective long-term drug carrier system within the follicular pathway, and concluded that "the effectiveness of skin antisepsis can be improved by standardized mechanically assisted application and prolonged exposure". See Table 3. 
Table 3. Deductions from modern hair follicle literature.

\begin{tabular}{|c|c|}
\hline Deductions & REF \\
\hline $\begin{array}{l}\text { Complete skin disinfection would "require the penetration of disinfectant throughout } \\
\text { the whole pilosebaceous canal" }\end{array}$ & $\begin{array}{r}{[94]} \\
{[100]}\end{array}$ \\
\hline Sebum production follows a defined circadian pattern & $\begin{array}{l}{[95]} \\
{[96]}\end{array}$ \\
\hline Temperature can influence the degree of drug deposition in the hair follicle. & [97] \\
\hline $\begin{array}{l}\text { Drug depletion in the hair follicle is a slow processes and can either } \\
\text { go deeper by penetration into deeper tissue layers or by flowing } \\
\text { out of the follicle with the sebum production }\end{array}$ & [98] \\
\hline Penetration of substances into the follicle can be increased when massage is applied. & [99] \\
\hline $\begin{array}{l}\text { As much as } 25 \% \text { of the cutaneous bacterial population can } \\
\text { be sequestered within the hair follicles }\end{array}$ & [101] \\
\hline Bacterial biofilms have been observed in the deeper portion of the human hair follicle. & [102] \\
\hline $\begin{array}{l}\text { The "swab method" for bacterial culture only identifies bacterial } \\
\text { colonies at the level of the superficial stratum corneum. }\end{array}$ & [103] \\
\hline $\begin{array}{l}\text { Large biofilm-like macro colonies have been observed } \\
\text { in the deep part of the hair follicle. }\end{array}$ & [104] \\
\hline Certain topicals could be detected for up to 4 days in a follicle after delivery. & [105] \\
\hline
\end{tabular}

\section{Conclusion: The Importance of the Ecological Reality of the Human Nares}

This review has established that there exists a substantial difference between purported Mupirocin resistance in clinical studies of MRSA and decolonization failure based on the commercial formulation of Mupirocin. Past medical researchers, most of whose critical findings concerning the decolonization of the human nares have either been forgotten or are not widely known, have cataloged a number of important factors that most likely explain a vast majority of Mupirocin nasal decolonization failures, even when the MIC of Mupirocin appears to be well within therapeutic range of the Mupirocin nasal (paraffin) formulation.

These factors can be summarized as follows;

1) Bacteria seek out places in the nares where traditional Mupirocin therapy and paraffin vehicles may have difficulty penetrating. Examples include the hair follicles, sebaceous glands, and the keratinocytes of the nares.

2) The existence of bacterial biofilm in the hair follicles and sebaceous glands also serve as defensive barriers to a Mupirocin insult.

3) Normal secretion of sebum from the sebaceous glands, inhibits Mupirocin and paraffin vehicles penetration into the hair follicles and sebaceous glands.

4) There is a circadian component to sebum secretion, such that Mupirocin therapy could be more effective when administered at specific times during the 24 hour cycle.

5) Historical Mupirocin nasal therapy administered t.i.d. (three times daily) shows significantly better outcomes than when administered b.i.d. (twice per day).

6) There is a synergistic benefit to the Mupirocin when compounded with a benzyl and phenoxy-ethanol cream formulation, and a greater synergistic benefit 
when compounded in a PEG ointment formulation, neither of which can be safely used in the nose.

When these factors (above) are taken into account, new treatment protocols can be proposed to augment Mupirocin nasal decolonization therapy. Such proposals would include:

1) Before Mupirocin nasal application, utilize a large warm moist swab or pad to remove any debris and crust in the Vestibulum nasi. Then use a large dry swab or pad in circular motion, to remove any remaining softened sebum from the openings of the hair follicles and sebaceous glands, thereby exposing the follicles and sebaceous glands prior to Mupirocin nasal delivery [21] [34] [44].

2) Dispense Mupirocin nasal into nares, and massage specifically into the hair follicles (vibrissae) of the Vestibulum nasi for 60 seconds by repeatedly squeezing nostril with thumb and fore-finger, not higher up in the mucosal area of the nostril. Also, gently massage into the vellus hair follicles and sebaceous gland on the outside of the Vestibulum nasi [95]-[105].

3) Apply Mupirocin nasal-t.i.d. to both nostrils (not b.i.d) and the outside of the Vestibulum nasi, and follow the protocol for at least five to seven days [76]-[87].

4) Utilize innovative medical devices to augment traditional topical pharmacologic therapy, to attempt to improve upon current pharma-alone therapies [106] [107].

\section{Conflict of Interest Statement}

Dr. Eric Bornstein is the Chief Science Officer and Chief Medical officer of Nomir Medical Technologies, the inventor of the $870 \mathrm{~nm} / 930 \mathrm{~nm}$ phototherapy device. Dr. Bornstein is employed by Nomir and retains stock in the company.

\section{References}

[1] Marchesi, J.R. (2014) The Human Microbiota and Microbiome. CABI. https://doi.org/10.1079/9781780640495.0000

[2] Maloy, S. and Moselio, S. (2006) The Era of Microbiology: A Golden Phoenix. International Microbiology, 9, 1.

[3] Shuter, J., Hatcher, V.B. and Lowy, F.D. (1996) Staphylococcus aureus Binding to Human Nasal Mucin. Infection and Immunity, 64, 310-318.

[4] Aly, R., Shinefield, H.I., Strauss, W.G. and Maibach, H.I. (1977) Bacterial Adherence to Nasal Mucosal Cells. Infection and Immunity, 17, 546-549.

[5] Aly, R., Shinefield, H.R., Litz, C. and Maibach, H.I. (1980) Role of Teichoic Acid in the Binding of Staphylococcus aureus to Nasal Epithelial Cells. The Journal of Infectious Diseases, 141, 463-465. https://doi.org/10.1093/infdis/141.4.463

[6] Peterson, A. (2006) Townsend. Ecologic Niche Modeling and Spatial Patterns of Disease Transmission.

[7] Watson, W.S. (1875) Diseases of the Nose and Its Accessory Cavities. Lewis.

[8] Ogston, A. (1882) Micrococcus Poisoning. Journal of Anatomy and Physiology, 17, 24-58.

[9] Rosenbach, A.J. (1884) Mikro-Qrganismenbei den Wund-Infections-Krankheiten des Menschen. J.F. Bergmann, Wiesbaden, 18.

[10] Baber, E.C. (1886) A Guide to the Examination of the Nose: With Remarks on the 
Diagnosis of Diseases of the Nasal Cavities. Chapter 1, Lewis.

[11] Cunningham, D.J. (1902) Cunningham's Textbook of Anatomy. W. Wood.

[12] Lack, H.L. (1906) The Diseases of the Nose and Its Accessory Sinuses. Longmans, Green.

[13] Braun-Falco, O., Plewig, G. and Wolff, H.H. (2013) Dermatology. Springer-Verlag, Berlin.

[14] Park, W.H. and Wright, J. (1889). Nasal Bacteria in Health. The Journal of Laryngology, Rhinology, and Otology, 13, 124-130. https://doi.org/10.1017/S1755146300166028

[15] Park, R. (1891) Pyogenic Organisms. Third Mütter Lecture, Series of 1890-91. Annals of Surgery, 13, 378. https://doi.org/10.1097/00000658-189101000-00075

[16] Galloway, J., et al. (1901) A Discussion on the Role of Cocci in the Pathology of the Skin. The British Medical Journal, 794-797.

[17] Ghosh, S. (2015) Neonatal Pustular Dermatosis: An Overview. Indian Journal of Dermatology, 60, 211.

[18] Schimmelbusch, C. (1895) A Guide to the Aseptic Treatment of Wounds. GP Putnam's Sons.

[19] Thomson, C. and Hewlett, R.T. (1895) Micro-Organisms in the Healthy Nose. Medico-Chirurgical Transactions, 78, 239. https://doi.org/10.1177/095952879507800115

[20] Shurly, E.L. (1905) A Treatise on Diseases of the Nose and Throat. Appleton.

[21] Allen, R.W. (1913) The Bacterial Diseases of Respiration, and Vaccines in Their Treatment. HK Lewis.

[22] Phillips, W.C. (1922) Diseases of the Ear, Nose and Throat: Medical and Surgical. Davis.

[23] Herzig, A.J. (1926) A Further Study and Clinical Report of the Use of Acriviolet in Diseases of the Upper Respiratory Tract and Ear. The Laryngoscope, 36, 445-452. https://doi.org/10.1288/00005537-192606000-00009

[24] Fleming, A. (1929) On the Antibacterial Action of Cultures of a Penicillium, with Special Reference to Their Use in the Isolation of B. Influenzae. British Journal of Experimental Pathology, 10, 226.

[25] Keilty, R.A. (1930) The Bacterial Flora of the Normal Conjunctiva with Comparative Nasal Culture Study. American Journal of Ophthalmology, 13, 876-879.

[26] Danbolt, N. (1932) Undersøkelser over staphylokokker: Med saerlighenblikkpåfurunkilosensepidemiologi. Dybwad.

[27] Davis, J.S. (1934) The Importance of Adequate Masking during Operation. Annals of Surgery, 100, 1008. https://doi.org/10.1097/00000658-193411000-00012

[28] Connor, J.I. (1935) Staphylococcal Infections of the Skin and Their Treatment. British Medical Journal, 2, 1195. https://doi.org/10.1136/bmj.2.3911.1195

[29] Gillespie, E.H., Devenish, E.A. and Cowan, S.T. (1939) Pathogenic Staphylococci Their Incidence in the Nose and on the Skin. The Lancet, 234, 870-873.

[30] Devenish, E.A. and Miles, A.A. (1939) Control of Staphylococcus aureus in an Operating-Theatre. The Lancet, 233, 1088-1094.

[31] Veach, H.O. (1940) Aluminum Chloride in Folliculitis of the Nose. California and Western Medicine, 52, 76.

[32] Sprawls, J.B. and Poe, C.F. (1943) A Study of the Germicidal and Bacteriostatic Properties of Some Commonly Used Antiseptics in Combination with Astringent 
Substances. Journal of the American Pharmaceutical Association, 32, 33-40. https://doi.org/10.1002/jps.3030320201

[33] Delafield, M.E., Straker, E. and Topley, W.W.C. (1941) Antiseptic Snuffs. British Medical Journal, 1, 145. https://doi.org/10.1136/bmj.1.4178.145

[34] Thomas, A.M. (1941) Treatment of Diphtheria Carriers with Sulphathiazole Snuff. British Medical Journal, 2, 687. https://doi.org/10.1136/bmj.2.4219.687

[35] Miles, A.A., Williams, R.E.O. and Clayton-Cooper, B. (1944) The Carriage of Staphylococcus (Ptogenes) aureus in Man and Its Relation to Wound Infection. The Journal of Pathology and Bacteriology, 56, 513-524. https://doi.org/10.1002/path.1700560405

[36] Taylor, P.H. and Hughes, K.E.A. (1944) Infective Dermatoses Treated with Penicillin. The Lancet, 244, 780-784.

[37] Gissane, W., Miles, A.A. and Williams, R.E.O. (1944) Design of Dressing Stations and Control of Wound Infection. British Journal of Industrial Medicine, 1, 90. https://doi.org/10.1136/oem.1.2.90

[38] Lovell, D.L. (1945) Skin Bacteria-Their Location with Reference to Skin Sterilization. Surgery Gynecology \& Obstetrics, 80, 174-177.

[39] Lovell, D.L. (1945) Skin Bacteria: Their Role in Contamination and Infection of Wounds. Archives of Surgery, 51, 78-80.

https://doi.org/10.1001/archsurg.1945.01230040083002

[40] Harkins, H.N. (1945) Cutis Grafts: Clinical and Experimental Studies on Their Use as a Reinforcing Patch in the Repair of Large Ventral and Incisional Herniae. Annals of Surgery, 122, 996. https://doi.org/10.1097/00000658-194512260-00010

[41] Hobbs, B.C., Carruthers, H.L. and Gough, J. (1947) Sycosisbarbae: Serological Types of Staphylococcus Pyogenes in Nose and Skin and Results of Penicillin Treatment. The Lancet, 250, 572-574.

[42] Moss, B., et al. (1948) Nose and Skin Carriage of Staphylococcus aureus in Patients Receiving Penicillin. The Lancet, 251, 320-325.

[43] Evans, C.A., Smith, W.M., Johnston, E.A. and Giblett, E.R. (1950) Bacterial Flora of the Normal Human Skin. Journal of Investigative Dermatology, 15, 305. https://doi.org/10.1038/jid.1950.105

[44] Anning, S.T. (1953) Recurrent Boils. British Medical Journal, 1, 721. https://doi.org/10.1136/bmj.1.4812.721

[45] Gould, J.C. (1955) The Effect of Local Antibiotic on Nasal Carriage of Staphylococcus pyogenes. Journal of Hygiene, 53, 379-385. https://doi.org/10.1017/S0022172400000863

[46] Williams, R.E.O., et al. (1959) Nasal Staphylococci and Sepsis in Hospital Patients. British Medical Journal, 2, 658. https://doi.org/10.1136/bmj.2.5153.658

[47] Varga, D.T. and Arthur, W. (1961) Suppression of Nasal, Skin, and Aerial Staphylococci by Nasal Application of Methicillin. Journal of Clinical Investigation, 40, 2209. https://doi.org/10.1172/JCI104447

[48] White, A. and Jeremy, S. (1963) Nasal Reservoir as the Source of Extranasal Staphylococci. Antimicrobial Agents and Chemotherapy.

[49] Montes, L.F. and Wilborn, WH. (1969) Location of Bacterial Skin Flora. British Journal of Dermatology, 81, 23-26. https://doi.org/10.1111/j.1365-2133.1969.tb12829.x

[50] Selwyn, S. and Harold, E. (1972) Skin Bacteria and Skin Disinfection Reconsidered. BMJ, 1, 136-140. https://doi.org/10.1136/bmj.1.5793.136

[51] Baader, A. and Garre, C. (1887) Uber Antagonistenunter den Bacterien. Corresp. BI. 
Schweiz. Ärzte, 13, 385-39.

[52] Vuillemin, P. (1889) Antibioseetsymbiose. CR Association Francaise pour L'Avancement des Sciences, 2, 525-543.

[53] Fuller, A.T., et al. (1971) Pseudomonic Acid: An Antibiotic Produced by Pseudomonas Fluorescens. Nature, 234, 416-417. https://doi.org/10.1038/234416a0

[54] Sutherland, R., Comber, K.R., Mizen, L.W., Slocombe, B. and Clayton, J.P. (1976) Pseudomonic Acid, an Antibiotic Produced by Pseudomonas Fluorescens. Proceedings of the 16th Interscience Conference on Antimicrobial Agents and Chemotherapy, Chicago.

[55] Hughes, J. and Graham, M. (1978) On the Mode of Action of Pseudomonic Acid: Inhibition of Protein Synthesis in Staphylococcus aureus. The Journal of Antibiotics, 31, 330-335. https://doi.org/10.7164/antibiotics.31.330

[56] Wuite, J., et al. (1983) Pseudomonic Acid: A New Topical Antimicrobial Agent. The Lancet, 322, 394.

[57] Dacre, J.E., Emmerson, A.M. and Jenner, E.A. (1983) Nasal Carriage of Gentamicin and Methicillin Resistant Staphylococcus aureus Treated with Topical Pseudomonic Acid. The Lancet, 322, 1036.

[58] Casewell, M.W. and Hill, R.L.R. (1983) Pseudomonic Acid and Control of Methicillin-Resistant Staphylococci. The Lancet, 322, 1312.

[59] Chirife, J., et al. (1983) In Vitro Antibacterial Activity of Concentrated Polyethylene Glycol 400 Solutions. Antimicrobial Agents and Chemotherapy, 24, 409-412. https://doi.org/10.1128/AAC.24.3.409

[60] Vaamonde, G., et al. (1982) An Examination of the Minimal Water Activity for Staphylococcus aureus ATCC 6538 P Growth in Laboratory Media Adjusted with Less Conventional Solutes. Journal of Food Science, 47, 1259-1262. https://doi.org/10.1111/j.1365-2621.1982.tb07661.x

[61] White, A.R., Beale, A.S., Boon, R.J., Griffin, K.E., Masters, P.J. and Sutherland, R. (1985) Antibacterial Activity of Mupirocin. Bactroban, 16, 19-36.

[62] Casewell, M.W., Hill, R.L.R. and Duckworth, G.J. (1984) The Effect of Mupirocin on the Nasal Carriage of Staphylococcus aureus. In: Mupirocin-A Novel Topical Antibiotic for the Treatment of Skin Infection, Royal Society of Medicine, International Congress and Symposium Series, London, Vol. 80, 149-154.

[63] Leyden, J.J. (1985) Studies on the Safety of Bactroban Ointment: Potential for Contact Allergy, Contact Irritation, Phototoxicity and Photo-Allergy. Bactroban ( $\mathrm{Mu}$ pirocin) Excerpta Medica Current Clinical Practice Series, 16, 68-71.

[64] Mellows, G. (1985) Pseudomonic Acid: Its Chemistry and Metabolism. In: Bactroban (Mupirocin) Proceedings of an International Symposium, Elsevier, Amsterdam, 3-10.

[65] Sutherland, R., Boon, R.J., Griffin, K.E., Masters, P.J., Slocombe, B. and White, A.R. (1985) Antibacterial Activity of Mupirocin (Pseudomonic Acid), a New Antibiotic for Topical Use. Antimicrobial Agents and Chemotherapy, 27, 495-498. https://doi.org/10.1128/AAC.27.4.495

[66] Casewell, M.W. and Hill, R.L.R. (1985) In Vitro Activity of Mupirocin ("Pseudomonic Acid") against Clinical Isolates of Staphylococcus aureus. Journal of Antimicrobial Chemotherapy, 15, 523-531. https://doi.org/10.1093/jac/15.5.523

[67] Casewell, M.R. and Hill, R.L.R. (1986) Elimination of Nasal Carriage of Staphylococcus aureus with Mupirocin ("Pseudomonic Acid")-A Controlled Trial. Antimicrob Chemother, 17, 36.

[68] Ayliffe, G.A.J., Duckworth, G.J., Brumfitt, W., Casewell, M.W., Cooke, E.M., Cook- 
son, B.D., Simmons, N.A., et al. (1986) Guidelines for the Control of Epidemic Methicillin-Resistant Staphylococcus aureus. Journal of Hospital Infection, 7, 193-201.

[69] Hattori, M., Miyachi, K., Hada, S., Kakiuchi, N., Kikuchi, F., Tsuda, Y. and Namba, T. (1987) Effects of Long-Chain Fatty Acids and Fatty Alcohols on the Growth on Streptococcus mutans. Chemical and Pharmaceutical Bulletin, 35, 3507-3510. https://doi.org/10.1248/cpb.35.3507

[70] Kato, N. and Shibasaki, I. (1980) The Antimicrobial Characteristics of 1-Alkanols. Journal of Antibacterial and Antifungal Agents, 8, 325-331.

[71] Kato, N., Yanagida, S., Okahara, M. and Shibasaki, I. (1978) Antibacterial Activity of Alcohols and Oxyethylated Alcohols. Journal of Antibacterial and Antifungal Agents, 6, 527-531.

[72] Kubo, I., Muroi, H., Himejima, H. and Kubo, A. (1993) Antibacterial Activity of Long-Chain Alcohols: The Role of Hydrophobic Alkyl Groups. Bioorganic \& Medicinal Chemistry Letters, 3, 1305-1308.

[73] Mates, A. (1974) The Effect of Alcohols on Growth and Lipase Formation by Staphylococcus aureus. Journal of Applied Bacteriology, 37, 1-6. https://doi.org/10.1111/j.1365-2672.1974.tb00409.x

[74] Togashi, N., Shiraishi, A., Nishizaka, M., Matsuoka, K., Endo, K., Hamashima, H. and Inoue, Y. (2007) Antibacterial Activity of Long-Chain Fatty Alcohols against Staphylococcus aureus. Molecules, 12, 139-148. https://doi.org/10.3390/12020139

[75] Menné, T. and Maibach, H.I. (1990) Exogenous Dermatoses: Environmental Dermatitis. CRC Press, Boca Raton.

[76] Hill, R.L.R., Duckworth, G.J. and Casewell, M.W. (1988) Elimination of Nasal Carriage of Methicillin-Resistant Staphylococcus aureus with Mupirocin during a Hospital Outbreak. Journal of Antimicrobial Chemotherapy, 22, 377-384. https://doi.org/10.1093/jac/22.3.377

[77] Bulanda, M., Gruszka, M. and Heczko, B. (1989) Effect of Mupirocin on Nasal Carriage of Staphylococcus aureus. Journal of Hospital Infection, 14, 117-124.

[78] Reagan, D.R., Doebbeling, B.N., Pfaller, M.A., Sheetz, C.T., Houston, A.K., Hollis, R.J. and Wenzel, R.P. (1991) Elimination of Coincident Staphylococcus aureus Nasal and Hand Carriage with Intranasal Application of Mupirocin Calcium Ointment. Annals of Internal Medicine, 114, 101-106. https://doi.org/10.7326/0003-4819-114-2-101

[79] Redhead, R.J., Lamb, Y.J. and Rowsell, R.B. (1990) The Efficacy of Calcium Mupirocin in the Eradication of Nasal Staphylococcus aureus Carriage. The British Journal of Clinical Practice, 45, 252-254.

[80] Doebbeling, B., Breneman, D., Marsh, R., Reagan, D. and Wenzel, R. (1992) October) Multi-Centre Study of Elimination of Staphylococcus aureus Nasal Carriage with Calcium Mupirocin Ointment in Healthy Subjects. Proceedings of the 32nd Interscience Conference on Antimicrobial Agents and Chemotherapy, Anaheim, 11-14 October 1992, 11-14.

[81] Scully, B.E., Briones, F., Gu, J.W. and Neu, H.C. (1992) Mupirocin Treatment of Nasal Staphylococcal Colonization. Archives of Internal Medicine, 152, 353. https://doi.org/10.1001/archinte.1992.00400140099022

[82] Doebbeling, B.N. (1994) Nasal and Hand Carriage of Staphylococcus aureus in Health Care Workers. Journal of Chemotherapy, 2, 11-17.

[83] Fernandez, C., Gaspar, C., Torrellas, A., Vindel, A., Saez-Nieto, J.A., Cruzet, F. and Aguilar, L. (1995) A Double-Blind, Randomized, Placebo-Controlled Clinical Trial to Evaluate the Safety and Efficacy of Mupirocin Calcium Ointment for Eliminating 
Nasal Carriage of Staphylococcus aureus among Hospital Personnel. Journal of Antimicrobial Chemotherapy, 35, 399-408. https://doi.org/10.1093/jac/35.3.399

[84] Van Rijen, M.M., Bonten, M., Wenzel, R.P. and Kluytmans, J.A. (2008) Intranasal Mupirocin for Reduction of Staphylococcus aureus Infections in Surgical Patients with Nasal Carriage: A Systematic Review. Journal of Antimicrobial Chemotherapy, 61, 254-261. https://doi.org/10.1093/jac/dkm480

[85] Kalmeijer, M.D., et al. (2002) Surgical Site Infections in Orthopedic Surgery: The Effect of Mupirocin Nasal Ointment in a Double-Blind, Randomized, PlaceboControlled Study. Clinical Infectious Diseases, 35, 353-358. https://doi.org/10.1086/341025

[86] Perl, T.M., et al. (2002) Intranasal Mupirocin to Prevent Postoperative Staphylococcus aureus Infections. New England Journal of Medicine, 346, 1871-1877. https://doi.org/10.1056/NEJMoa003069

[87] Konvalinka, A., Errett, L. and Fong, I.W. (2006) Impact of Treating Staphylococcus aureus Nasal Carriers on Wound Infections in Cardiac Surgery. Journal of Hospital Infection, 64, 162-168.

[88] Bode, L.G., Kluytmans, J.A., Wertheim, H.F., Bogaers, D., Vandenbroucke-Grauls, C.M., Roosendaal, R., et al. (2010) Preventing Surgical-Site Infections in Nasal Carriers of Staphylococcus aureus. The New England Journal of Medicine, 362, 9-17. https://doi.org/10.1056/NEJMoa0808939

[89] http://www.medicines.org.uk/emc/medicine/2027

[90] http://www.accessdata.fda.gov/drugsatfda_docs/label/2015/050703s016lbl.pdf

[91] Mariana, et al. (2009) Evaluation of Modified Congo Red Agar for Detection of Biofilm Produced by Clinical Isolates of Methicillin Resistance Staphylococcus aureus. African Journal of Microbiology Research, 3, 330-338.

[92] Arciola, C.R., et al. (2002) Detection of Slime Production by Means of an Optimised Congo Red Agar Plate Test Based on a Colourimetric Scale in Staphylococcus Epidermidis Clinical Isolates Genotyped for Ica Locus. Biomaterials, 23, 4233-4239.

[93] Zhou, S., et al. (2013) Analysis of S. Epidermidisica A and Ica D Genes by Polymerase Chain Reaction and Slime Production: A Case Control Study. BMC Infectious Diseases, 13, 242. https://doi.org/10.1186/1471-2334-13-242

[94] Kearney, J.N., et al. (1984) The Follicular Distribution and Abundance of Resident Bacteria on Human Skin. Microbiology, 130, 797-801. https://doi.org/10.1099/00221287-130-4-797

[95] Le Fur, I., Reinberg, A., Lopez, S., Morizot, F., Mechkouri, M. and Tschachler, E. (2001) Analysis of Circadian and Ultradian Rhythms of Skin Surface Properties of Face and Forearm of Healthy Women. Journal of Investigative Dermatology, 117, 718-724. https://doi.org/10.1046/j.0022-202x.2001.01433.x

[96] Latreille, J., Guinot, C., Robert-Granie, C., Le Fur, I., Tenenhaus, M. and Foulley, J.L. (2004) Daily Variations in Skin Surface Properties Using Mixed Model Methodology. Skin Pharmacology and Physiology, 17, 133-140. https://doi.org/10.1159/000077240

[97] Vogt, A., et al. (2005) Follicular Targeting-A Promising Tool in Selective Dermatotherapy. Journal of Investigative Dermatology Symposium Proceedings, 10, 252255. https://doi.org/10.1111/j.1087-0024.2005.10124.x

[98] Lademann, J., et al. (2006) Hair Follicles-A Long-Term Reservoir for Drug Delivery. Skin Pharmacology and Physiology, 19, 232-236. https://doi.org/10.1159/000093119

[99] Lademann, J., Richter, H., Teichmann, A., et al. (2007) Nanoparticles-An Efficient 
Carrier for Drug Delivery into the Hair Follicles. European Journal of Pharmaceutics and Biopharmaceutics, 66, 159-164.

[100] Broeke-Smits, N.J.P., et al. (2010) Hair Follicles as a Niche of Staphylococcus aureus in the Nose; Is a More Effective Decolonization Strategy Needed? Journal of Hospital Infection, 76, 211-214.

[101] Lange-Asschenfeldt, B., et al. (2011) Distribution of Bacteria in the Epidermal Layers and Hair Follicles of the Human Skin. Skin Pharmacology and Physiology, 24, 305-311. https://doi.org/10.1159/000328728

[102] Matard, B., et al. (2013) First Evidence of Bacterial Biofilms in the Anaerobe Part of Scalp Hair Follicles: A Pilot Comparative Study in Folliculitis Decalvans. Journal of the European Academy of Dermatology and Venereology, 27, 853-860. https://doi.org/10.1111/j.1468-3083.2012.04591.x

[103] Alexeyev, O.A. (2013) Bacterial Landscape of Human Skin: Seeing the Forest for the Trees. Experimental Dermatology, 22, 443-446. https://doi.org/10.1111/exd.12160

[104] Jahns, A.C., et al. (2014) Microbiology of Folliculitis: A Histological Study of 39 Cases. Apmis, 122, 25-32. https://doi.org/10.1111/apm.12103

[105] Ulmer, M., et al. (2014) New Strategies for Preoperative Skin Antisepsis. Skin Pharmacology and Physiology, 27, 283-292. https://doi.org/10.1159/000357387

[106] Narayan, V.A., et al. (2013) Beyond Magic Bullets: True Innovation in Health Care. Nature Reviews Drug Discovery, 12, 85-86. https://doi.org/10.1038/nrd3944

[107] Bornstein, E. (2014) Photo-Biologic Inhibition of Biofilm Formation in MRSA as a Potential Amplification of Mupirocin Nasal Carriage Eradication Therapy. Trends in Photochemistry \& Photobiology, 16, 35-45.

Submit or recommend next manuscript to SCIRP and we will provide best service for you:

Accepting pre-submission inquiries through Email, Facebook, LinkedIn, Twitter, etc. A wide selection of journals (inclusive of 9 subjects, more than 200 journals)

Providing 24-hour high-quality service

User-friendly online submission system

Fair and swift peer-review system

Efficient typesetting and proofreading procedure

Display of the result of downloads and visits, as well as the number of cited articles

Maximum dissemination of your research work

Submit your manuscript at: http://papersubmission.scirp.org/

Or contact aim@scirp.org 